\title{
Instrumental avoidance acquisition by goldfish in a Y-maze using explicit and response-contingent cues
}

\author{
D. J. ZERBOLIO, JR., and L. L. WICKSTRA \\ University of Missouri-St. Louis, St. Louis, Missouri 63121
}

\begin{abstract}
In two experiments, goldfish learned a discriminated avoidance response in a Y-maze. When alternative response alleys were simultaneously and differentially cued at trial onset, the goldfish learned to swim to the alley associated with US omission. When alternative response alleys were not differentially cued at trial onset and the US association cue was contingent upon an initial response to one of the alternatives, goldfish learned, following the initial response, to stay in the initially chosen alley when the response-contingent cue indicated US omission, but to leave the initially chosen alley and swim to the alternative alley when the response-contingent cue indicated US pairing.
\end{abstract}

Ryback (1969a, 1969b) and Sahagian and Ingle (1977) have reported that goldfish can learn a discriminated avoidance response in a Y-maze. However, their use of a blocked alley with "nose bump" negative reinforcement and their provision of minimum information about practice conditions make interpretation difficult. More recently, Zerbolio and Wickstra (1979b) showed that, with a conventional shock US as the reinforcer, and with the simultaneous presentation of differential cues representing US pairing $\left(\mathrm{S}^{-}\right)$and US omission $(\mathrm{S}+)$, goldfish learned to swim to the $S+$ alley. The preponderance of $\mathrm{S}+$ choices was interpreted as clear evidence for the acquisition of a discriminated avoidance response. But the only response consequence in that study was US omission when the goldfish swam to the S+ alley. One of the variables traditionally thought to affect avoidance is cue termination (Scobie \& Fallon, 1974; Woodard \& Bitterman, 1973; Zerbolio \& Wickstra, $1978 \mathrm{a}, 1978 \mathrm{~b})$. The first experiment examined the role of response-contingent $S+$ and/or $S$ - termination along with US omission on goldfish $\mathrm{Y}$-maze discriminated avoidance acquisition. The study both replicated the earlier finding using a shock US and extended the knowledge of the variables affecting acquisition in simultaneous presentation tasks.

\section{EXPERIMENT 1}

\section{Method \\ Subjects. Thirty-two 5-6-cm goldfish, obtained from Ozark Fisheries and housed in individual $7.5 \times 11.5 \times 12.5 \mathrm{~cm}$ deep}

The authors wish to thank D. E. McAllister for her helpful critique and suggestions in preparing this manuscript. Reprint requests should be sent to the first author, Department of Psychology, University of Missouri-St. Louis, 8001 Natural Bridge Road, St. Louis, Missouri 63121. aquaria, served as subjects. Housing was well aerated and filtered, with both temperature $\left(21.1 \mathrm{C}^{\circ}\right)$ and $\mathrm{pH}(7 \pm .1)$ held constant. The animals were fed daily.

Apparatus. Two identical Y-mazes constructed of $.635-\mathrm{cm}$ clear plastic with three alleys 120 deg apart were used. Each alley was $8.7 \mathrm{~cm}$ wide, $10 \mathrm{~cm}$ deep, and from the exact center $20 \mathrm{~cm}$ long (all inside dimensions). Each maze contained a three-projection hurdle, $5 \mathrm{~cm}$ high, which extended $6.5 \mathrm{~cm}$ horizontally into each alley and then sloped at $45 \mathrm{deg}$ to the alley floor. The internal sides of each alley were lined with $9 \times 16.5 \mathrm{~cm} 22$-ga stainless steel plates (six in all), providing for US delivery. A photocell detector, focused across each hurdle at the beginning of the 45-deg slope, served to monitor shuttling activity. Differential illumination cues were provided by three $7-\mathrm{W} 110-\mathrm{V}$ ac Christmas tree bulbs (white, red, and green) at the end wall of each alley (nine lamps in all). Each cue lamp was individually controlled and mounted so light did not project on other alleys. Clear plastic tops prevented the goldfish from jumping out of the maze. Water level was maintained at $7 \mathrm{~cm}(2 \mathrm{~cm}$ over the hurdle) at all times. For further information and a diagram, see Zerbolio and Wickstra (1979b).

Procedure. All subjects were tested for 60 trials a day for 10 days. The intertrial interval (ITI) was variable, with a mean of $60 \mathrm{sec}$ and a range of 20 to $100 \mathrm{sec}$. During the ITI, all alleys were illuminated by the white lamps. At trial onset, all white lamps were extinguished, including that in the alley occupied by the fish at that time, as indicated by the last photobeam broken. The start alley, or alley occupied by the fish at trial onset, remained dark during the trial period. Simultaneous with trial onset, the two remaining alleys were differentially illuminated, red or green. For half the subjects, the green stimulus served as the $\mathbf{S}+$ stimulus, unpaired with shock, and for the remainder, the red stimulus served as the $\mathrm{S}+$. The remaining colored stimulus was the $\mathrm{S}-$ stimulus, paired with shock. The $S+$ alley occurred equally often on the right and left of the start alley in a Gellerman series. Each trial consisted of a 10 -sec period followed by two $200-\mathrm{msec} 6-\mathrm{V}$ ac $(.695 \mathrm{~V} / \mathrm{cm})$ pulses with an intershock interval of $800 \mathrm{msec}$, constituting a total trial duration of $11.2 \mathrm{sec}$. If the subject swam to the $\mathrm{S}+$ alley at any time during the initial 10 -sec period of the trial, no matter what responses occurred before or after the $S+$ response, the US was not presented. Thus, the subject received shock if and only if, at the end of $10 \mathrm{sec}$, it was in either the start alley or the S- alley and had not previously entered the S+ alley. Further, if the subject received the first US pulse, it could avoid the second US pulse by swimming to the S+ alley in the 800 -msec intershock interval. However, only those responses occurring in the first 
$10 \mathrm{sec}$ of each trial were recorded. This procedure is identical to that used earlier by Zerbolio and Wickstra (1979b).

For half the subjects, specific stimuli were changed (c) contingent upon their swimming to a particular alley, whereas for the remainder, no change (nc) occurred. In all cases, a change was the termination of the cue that rendered the alley dark and comparable to the start alley. For half the subjects, swimming to the $\mathrm{S}+$ alley produced a change in the $S+$ cue from illumination to dark $(S+c)$, whereas for the remainder, no change occurred $\left(S+{ }_{n c}\right)$. Comparably, for half the subjects, swimming to the $S-$ alley produced a change from illumination to darkness $(S-)$, whereas for the remainder, no change $\left(S-{ }_{n c}\right)$ occurred. Termination conditions were factorially arranged so as to constitute four separate treatment conditions of eight subjects each. The number of trials where subjects initially swam to the $\mathrm{S}+$ or $\mathrm{S}-$ alley and the number of double responses where the goldfish visited both the $\mathrm{S}+$ and $\mathrm{S}-$ alley were recorded. Additionally, the number of alley changes during the ITI was recorded.

\section{Results and Discussion}

Figure 1 presents the daily mean performances, based on 60 trials per day, for initial responses to the $\mathrm{S}+$ alley, initial responses to the $\mathrm{S}-$ alley, and responses to both alleys (double responses) for all groups. Each measure was analyzed with a repeatedmeasures ANOVA, with the $\mathrm{S}+$ and the $\mathrm{S}$ - termina-

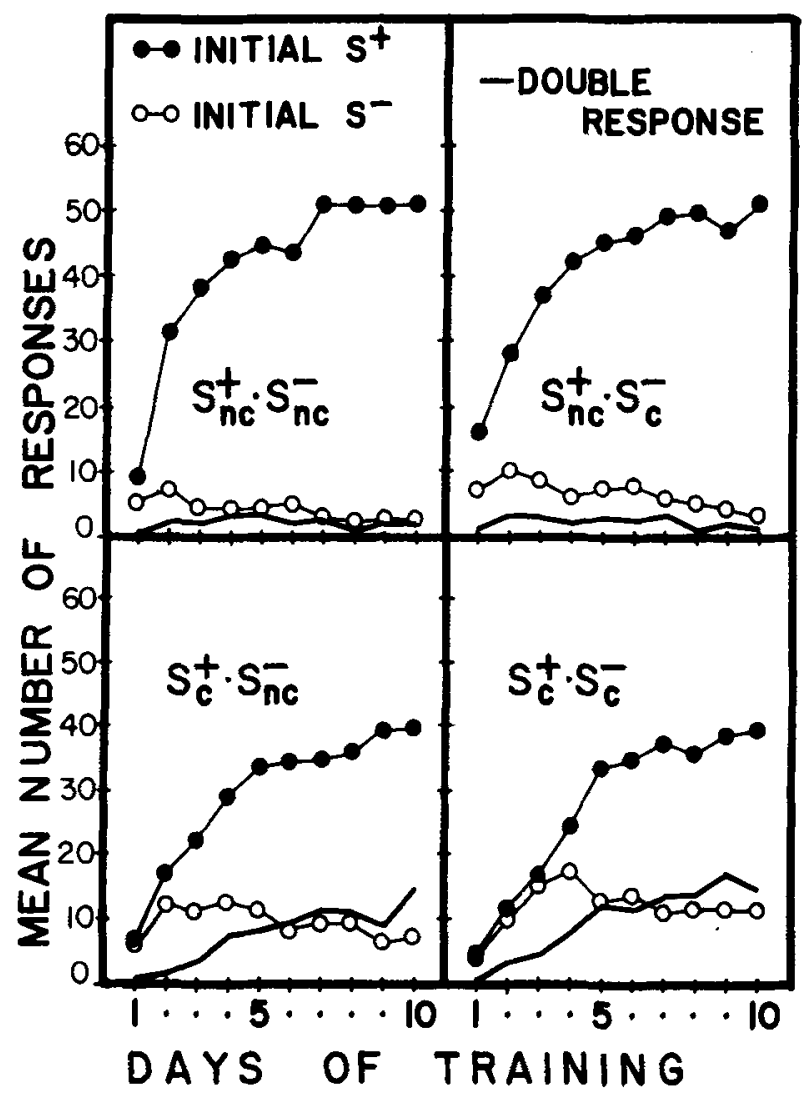

Figure 1. Mean number of the 60 daily trials for each group in which the initial response was to the alley paired with US omission (initial S+), to the alley paired with the US (initial $S_{-}$), and when responding occurred to both the $S+$ and $S-$ alleys (double response). tion conditions as the between-subjects factors and days of training as the within-subject factor.

Initial $\mathbf{S}+$ responses. All groups acquired, with training, a decided preference for the S+ alley. Additionally, as shown in Figure 1, the groups in which the $\mathrm{S}+$ cue was not changed $\left(\mathrm{S}+{ }_{\mathrm{nc}}\right)$ had initial response levels higher than those groups with $\mathrm{S}+$ responsecontingent change $(\mathrm{S}+\mathrm{c})$. These observations were confirmed by the analysis which yielded a significant effect for days of training $[F(9,252)=120.06, p<.01]$ and a significant effect of the $\mathrm{S}+$ change factor $[F(1,28)=20.74, p<.01]$. No other reliable effects were observed.

Initial $\mathbf{S}$ - responses. The initial $\mathrm{S}$ - responses, as shown in Figure 1, increased slightly and then decreased for all groups, but, overall, the $\mathrm{S}$ - response level was higher when an $S+$ response changed the $\mathrm{S}+$ cue $\left(\mathrm{S}+{ }_{c}\right)$ than when it did not $\left(\mathrm{S}+{ }_{n c}\right)$. These observations were confirmed by the $\mathrm{S}$ - analysis, which indicated that both the days-of-training $[\mathrm{F}(9,252)=$ $5.14, \mathrm{p}<.01]$ and the $S+$ change factors $[F(1,28)=$ $25.43, p<.01]$ were significant. No other reliable effects were observed.

Double responses. Figure 1 also shows the mean number of trials per day when goldfish swam to both the $\mathrm{S}+$ and $\mathrm{S}$ - alleys. When the $\mathrm{S}+$ stimulus did not change contingent upon the response, animals rarely responded after their initial alley selection. However, when the $\mathrm{S}+$ stimulus terminated contingent upon the response, there was an increasing tendency for animals to leave the initial choice alley and swim to another alley. This effect was confirmed by the analysis, which found significantly higher double-response rates when the $\mathrm{S}+$ stimulus changed than when it did not $[F(1,28)=12.25, \mathrm{p}<.01]$. Additionally, a significant days-of-training effect $[F(9,252)=8.89$, $\mathrm{p}<.01]$ and a $\mathrm{S}+$ Change by Days-of-Training interaction $[F(9,252)=8.95, p<.01]$ were observed. There were no other reliable effects.

ITI responses. A further analysis considered the mean number of ITI responses. No differences between groups were observed. Overall, there was a slight, but reliable, drop in the mean number of ITI responses, from 54.2 on the first to 44.3 on the last day of training $[F(9,252)=2.04, p<.05]$. No other reliable differences were found.

Taken as a whole, it is clear that, in a Y-maze, the goldfish learned rapidly to leave a darkened alley and swim to the alternative alley displaying the S+ cue rather than to the alternative showing the $\mathrm{S}$ cue. The simplest explanation for these results is that the goldfish acquired a conditioned aversion for all of the cues paired with the US. Thus, early in training, both the dark alley cue and the $S$ - cue became aversive because both were paired with the US. The failure to find any evidence showing differential effects between the $S-n c$ and $S-{ }_{c}$ conditions indicates 
that the aversiveness of the $\mathrm{S}-$ and dark cue, both of which occurred in the $S-{ }_{c}$ condition, were equivalent to the $S-n c$ cue condition. Thus, changing the $S-$ cue to dark can be interpreted as substituting one aversive cue (dark) for another $(\mathrm{S}-$ ).

Given the conditioned aversion to both the dark alley cue and $\mathrm{S}$ - cue, the actively responding animal simply escapes the dark start alley cue by leaving and avoids the $S-$ cue by approaching the nonaversive $\mathrm{S}+$ cue, which results in successful avoidance. As long as the $S+$ cue does not change, the goldfish would not be expected to leave the $S+$ alley because leaving would require the animal to approach either the dark start alley or the S- alley, both aversive cues. However, if the $\mathrm{S}+$ alley changes to dark contingent upon alley entry, although the animal has initially correctly approached the $\mathrm{S}+$ alley, the response-contingent change punishes the $\mathrm{S}+$ approach response by changing to a dark aversive cue condition. As a result, at least two behavioral effects would be expected. First, the $\mathrm{S}+_{\mathrm{c}}$ condition would be expected to attenuate initial $\mathrm{S}+$ preference, and second, the animal would be expected to leave the darkened alternative alley. The results of Experiment 1 support both of these expectations. Acquisition was significantly attenuated in both groups tested with the $S t_{c}$ cue condition as compared with the $S+n c$ condition, and the $S+{ }_{c}$ groups, following their initial $\mathrm{S}+$ choice, learned to leave the $\mathrm{S}+$ alley with a second response, whereas the $\mathrm{S}+_{\mathrm{nc}}$ groups did not learn to double respond. The difference in double-response acquisition can be attributed solely to the $\mathrm{S}+_{c}$ vs. $\mathrm{S}+{ }_{\mathrm{nc}}$ cue difference, since no other variables were found to have reliable effects. This finding strongly implies that $\mathrm{S}+_{c}$ groups learned a discriminated second response to the response-contingent $S+{ }_{c}$ cue. The fact that $S+n c$ groups did not acquire the doubleresponse pattern strongly suggests that goldfish may be able to acquire a discriminated avoidance based solely on a differential response-contingent cue. A second experiment was designed to test this hypothesis.

\section{EXPERIMENT 2}

To demonstrate acquisition of a discriminated avoidance response based solely on a responsecontingent cue, goldfish would have to learn to respond in a situation where no differential US association information is present at trial onset, but where this information becomes available after the animal has made an initial response. The Y-maze lends itself well to such a requirement, since trial onset can be indicated to the goldfish in the alley it occupies (the start alley), while simultaneously the alternative response alleys can be indicated as different from the start alley but not different from each other. Only after the goldfish leaves the start alley and swims to one of the equivalently indicated alternative alleys would the cue differentiating US association be presented. If goldfish learn to use such a responsecontingent cue efficiently, they would be expected to stay in the initially chosen alternative alley if the response-contingent cue is $\mathrm{S}+$, whereas if the responsecontingent cue is $S-$, they would be expected to leave the alley and correct by swimming to the $\mathrm{S}+$ alley. But other behavior patterns are possible. One pattern could occur because the animal would be faced at trial onset with an insoluble discrimination insofar as locating the $\mathrm{S}+$ alley on the initial response. In this case, goldfish could simply refuse to leave the start alley, resulting in no avoidance acquisition at all. A second pattern might be that the goldfish would leave the start alley but not use the differential responsecontingent cue. If that occurred, and given that the goldfish makes only one response per trial, it would avoid on half the trials by chance. A third pattern of behavior could produce substantial avoidance without discrimination. If the animal were to visit each alternative, that is, double respond on each trial, it could avoid the US on each trial. This behavior pattern would be evidence of response learning but could not be viewed as stimulus specific. Experiment 2 was designed to determine if goldfish can learn to avoid using a response-contingent cue procedure and, if not, which of the above indicated behavior patterns, if any, develop.

\section{Method}

Subjects. Thirty-two 5-6-cm goldfish, from the same source, housed, and maintained as in the previous experiment, served as subjects.

Apparatus. The apparatus was the same as that used in the previous experiment.

Procedure. All animals were tested for 60 trials a day for 10 days with a VI $60-$ sec ITI. During the ITI, all alleys were illuminated with white light. With the following exceptions, all procedural details were identical to the previous experiment.

At trial onset, all white illumination was extinguished, and simultaneously the start alley (the one occupied by the goldfish) was illuminated with one color (green for half of the subjects, red for the remainder) and both the remaining alleys were illuminated with a second color (red for half of the subjects, green for the remainder). Thus, both alternative alleys, although different in color from the start alley, were simultaneously illuminated with the same color. Start alley illumination remained constant during the entire trial. Depending on the treatment condition, the illumination of a specific alternative alley either was not changed (nc) or was changed $(c)$ to dark, contingent upon alley entry. Change or no change in alternative alley illumination served as the differential response-contingent cue. Alternative alley cues, changed or not, were always different from the constant illumination in the start alley. The two postresponse cue conditions, $c$ or ac, for both the $S-$ and $S+$ alleys were factorially arranged to constitute four different treatment procedures.

Only two of the above treatments, $S+_{n c} \cdot S-{ }_{c}$ and $S+{ }_{c} \cdot S-{ }_{n c}$, provided differential response-contingent information. The remaining two treatments, $\mathrm{S}+_{n c} \cdot S-{ }_{n c}$ and $\mathrm{S}+_{c} \cdot S-{ }_{c}$, provided equivalent postresponse cues in the alternative alleys but were not identical with respect to information about avoidance. In the $\mathrm{S}+_{\mathrm{nc}} \cdot \mathrm{S}-_{\mathrm{nc}}$ treatment, the animal gained no usable information beyond that available at trial onset no matter how it responded, whereas in the $\mathrm{S}+_{c} \cdot \mathrm{S}-{ }_{c}$ treatment, if the goldfish double responded 
on each trial, illumination in both alternative alleys would be extinguished. If double responding can be learned, the feedback information necessary to indicate that both alleys had been visited is provided in the $S+_{c} \cdot S-{ }_{c}$ condition.

The $\mathrm{S}+$ alley was presented equally often on the left and right of the start alley in a Gellerman series, although at trial onset its position was not differentially cued.

In addition to identifying where the goldfish went on its initial response, second responses were also recorded for two classes: leaving the $\mathrm{S}+$ alley following initial $\mathrm{S}+$ alley choice and correcting to the $S+$ alley following an initial $S$ - alley choice.

\section{Results and Discussion}

Initial responses. The initial-response analysis considered only the first response made following trial onset. Figure 2 shows the daily means of all four treatment groups for total responses (swimming to one of the alternative alleys) and, of the total responses, the mean number of initial responses to the S+ alley.

The total-response performance curves show that all groups learned very quickly to leave the start alley and swim to one of the alternative alleys. However, the groups receiving differential response-contingent information $\left(\mathrm{S}+{ }_{n c} \cdot S-c\right.$ and $\left.\mathrm{S}+_{c} \cdot S-{ }_{n c}\right)$ responded on slightly more trials overall than the groups not receiving differential information $\left(\mathrm{S}+{ }_{n c} \cdot \mathrm{S}-{ }_{n c}\right.$ and $\left.\mathrm{S}+{ }_{c} \cdot \mathrm{S}-{ }_{c}\right)$. The groups appear to be equal with respect to the number of initial $\mathrm{S}+$ responses. These

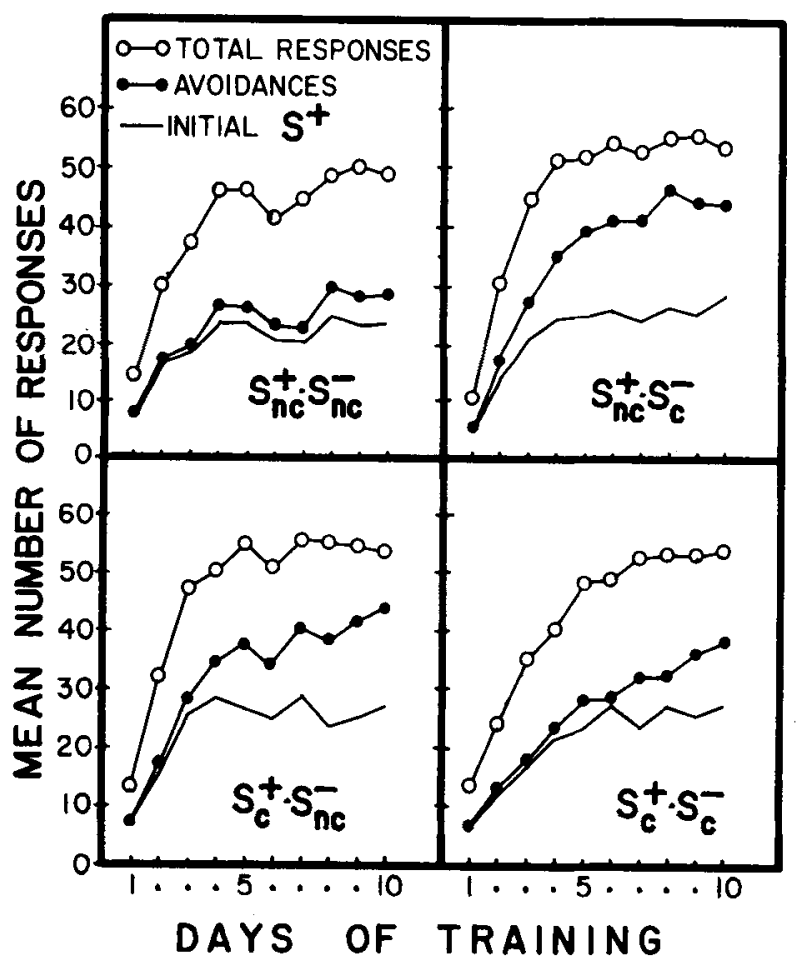

Figure 2. Mean number of the 60 daily trials for each group in which a response was made to one of the alternative alleys (total responses), in which the initial response was to the $S+$ alley, and in which a response occurred at some time during the trial to the S+ alley (avoidances). curves may be taken as representative also of initial $\mathrm{S}$ - responses because, as the analyses below indicate, no differences were found between mean numbers of initial $\mathrm{S}+$ and $\mathrm{S}-$ responses either within a group or between groups.

These observations were confirmed by a four-way ANOVA, with $\mathrm{S}+$ and $\mathrm{S}-$ change conditions as the two between-subjects factors, and $\mathrm{S}+$ vs. S- alleys and 10 days of training as the two repeated-measures factors. A significant Days-of-training effect $[F(9,252)$ $=165.32, \mathrm{p}<.01]$ confirmed the increase in total responses for all groups. Additionally, a significant $\mathrm{S}+$ by $\mathrm{S}-$ Change interaction $[\mathrm{F}(1,28)=7.06, \mathrm{p}<.05]$ showed that the groups differed in total responses. A partition of this interaction showed that the groups receiving differential information did not differ $\left(S+_{n c} \cdot S-c, \quad \bar{X}=47.05 ; S+_{c} \cdot S-n c, \quad \bar{X}=46.01 ;\right.$ $F<1)$ and the groups not receiving differential information did not differ $\left(S+{ }_{n c} \cdot S-{ }_{n c}, \bar{X}=40.90\right.$; $\left.\mathrm{S}+_{c} \cdot \mathrm{S}-{ }_{c}, \overline{\mathrm{X}}=42.59 ; \mathrm{F}<1\right)$, but the combined differentially cued groups were significantly higher $[F(1,28)=7.23, p<.05]$ in total responses $(\bar{X}=$ $46.53)$ than the combined groups not receiving differential information $(\bar{X}=41.74)$.

The repeated-measures factor involving initial S+ and initial $\mathbf{S}-$ responses was not found significant as a main effect, nor did it interact with any other factor in the analysis, indicating that the positioning of the $\mathrm{S}+$ and $\mathrm{S}-$ alleys to the left or right of the starting alley was successfully masked by the procedure at trial onset. No other main effects or interactions were significant.

Avoidance responses. The mean daily avoidances for all groups are also shown in Figure 2. All groups increased in avoidance performance with training. However, the groups receiving differential responsecontingent information $\left(\mathrm{S}+{ }_{n c} \cdot \mathrm{S}-{ }_{c}\right.$ and $\left.\mathrm{S}+{ }_{c} \cdot \mathrm{S}-{ }_{n c}\right)$ avoided more often than the groups without such information $\left(S+{ }_{n c} \cdot S-n c\right.$ and $\left.S+_{c} \cdot S-c\right)$.

A three-way ANOVA, with $\mathrm{S}+$ and $\mathrm{S}-$ change conditions as the between-subjects factors and days of training as the repeated-measures factor, confirmed these observations. A significant effect over days $[F(9,252)=8.26, p<.01]$ confirmed the general avoidance increase. In addition, a significant $\mathrm{S}+$ by $S-$ Change interaction was found $[F(1,28)=24.08$, $\mathrm{p}<.01]$. Partitioning this interaction found that the differentially cued groups did not differ $\left(\mathrm{S}+{ }_{\mathrm{nc}} \cdot \mathrm{S}-{ }_{\mathrm{c}}\right.$, $\left.\overline{\mathrm{X}}=34.31 ; \mathrm{S}+_{\mathrm{c}} \cdot \mathrm{S}-{ }_{\mathrm{nc}}, \overline{\mathrm{X}}=32.28 ; \mathrm{F}<1\right)$ and the groups without differential information did not differ $\left[\mathrm{S}+_{\mathrm{nc}} \cdot \mathrm{S}-{ }_{\mathrm{nc}}, \overline{\mathrm{X}}=23.15 ; \mathrm{S}+_{\mathrm{c}} \cdot \mathrm{S}-{ }_{\mathrm{c}}, \overline{\mathrm{X}}=25.91\right.$; $\mathrm{F}(1,28)=1.21, \mathrm{p}>.05]$, but the combined differentially cued groups avoided on more trials $(\bar{X}=33.30)$ than the combined groups not receiving differential information $(\bar{X}=24.53)[F(1,28)=24.39, p<.01]$. No other reliable effects were found.

Although the differentially cued groups were found to be superior in avoidance performance to the groups 
not receiving differential response-contingent information, that finding alone does not necessarily mean that the differentially cued groups were using the cue information efficiently. To avoid shock, the procedure demanded that goldfish visit the $\mathrm{S}+$ alley at some time during the 10-sec shock-free period of each trial. When, by chance, goldfish swam to the $\mathrm{S}+$ alley as the first response, the US was omitted for the trial and any additional swimming responses were entirely gratuitous. If, however, the initial choice was to the S- alley, to avoid, the goldfish had to respond a second time by leaving the $\mathrm{S}-$ alley and swimming to the $\mathrm{S}+$ alley within the $10-\mathrm{sec}$ shock-free trial period. Efficient cue utilization would be for the animal to stay in the initially chosen alley if the responsecontingent cue indicated $\mathrm{S}+$, but to leave and correct its alley position if the response-contingent cue was $\mathrm{S}-$. However, another response pattern which would effectively augment avoidance would be to swim to both alternative alleys on all trials, independent of the initial response-contingent cue. An analysis of the second responses was completed to determine how the goldfish augmented their avoidance performance above the chance level of the initial $\mathrm{S}+$ response.

Second responses. The starting point for a second response depended on which alley the goldfish entered on its initial response. If the initial response was to the $\mathrm{S}+$ alley, a second response involved leaving the $\mathrm{S}+$ alley (leave $\mathrm{S}+$ ), which, of course, had no effect on avoidance. If, however, the initial response was to the S- alley, the animal had to leave the Salley and correct to the $S+$ alley (correct to $S+$ ) to avoid. The daily mean leave-S+ and correct-to-S+ responses for all groups are shown in Figure 3. Since the $\mathrm{S}+{ }_{n c} \cdot \mathrm{S}-_{\mathrm{nc}}$ group, shown in the top left panel of Figure 3, received no cue changes after trial onset no matter what responses they made, their leave-S+ and correct-to-S+ performances constitute control levels for both second-response measures. As the $\mathrm{S}+{ }_{n c} \cdot \mathrm{S}-{ }_{n c}$ control performances show, the leave-S+ and correct-to-S+ levels are not equivalent. Leaving the $\mathrm{S}+$ alley following an initial $\mathrm{S}+$ response involves only activity, whereas correcting to the $\mathrm{S}+$ alley following an initial $\mathrm{S}$ - choice involves not only swimming out of the S- alley, but specifically swimming to the $\mathrm{S}+$ and not the start alley.

Inspection of Figure 3 shows that both groups that did not receive differential response-contingent information following their initial response $(S+n c \cdot S-n c$ and $\mathrm{S}+\mathrm{c} \cdot \mathrm{S}-\mathrm{c}$ ) were quite similar in that both learned to leave the $S+$ alley much more often than they corrected to the $S+$ alley. Both groups that did receive differential response-contingent information following their initial response $\left(\mathrm{S}+{ }_{n c} \cdot \mathrm{S}-_{c}\right.$ and $\left.\mathrm{S}+_{\mathrm{c}} \cdot \mathrm{S}-{ }_{\mathrm{nc}}\right)$, while similar to each other, differed strikingly from the nondifferentially cued groups. For them, if the differential cue indicated S+, they did not leave, whereas if the differential cue indicated

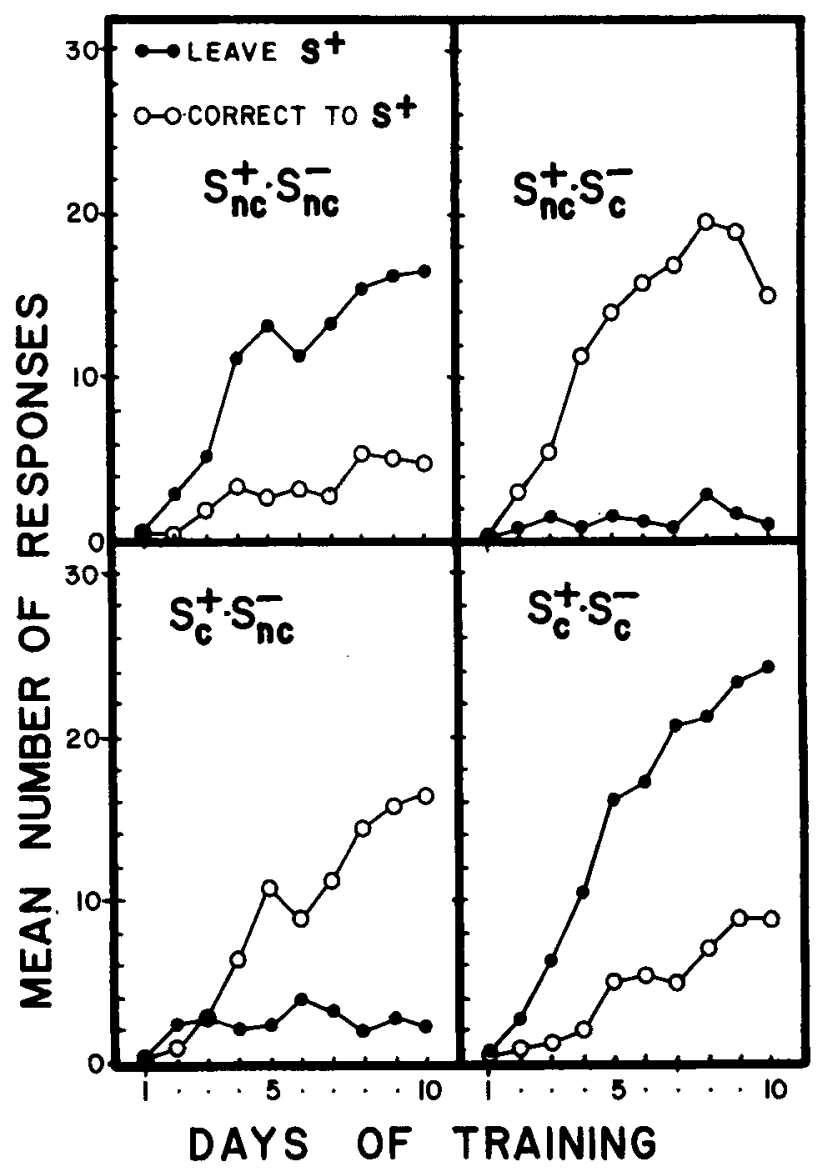

Figure 3. Mean number of trials per day for each group for each of two second-response classes, leaving the $S+$ alley following an initial response to the $S+$ alley and correcting to the $S+$ alley following an initial response to the $S-$ alley.

S-, they left the S- alley and specifically and differentially corrected their alley location by swimming to the $\mathrm{S}+$ alley. The following three-way ANOVAs confirmed all of these observations.

For the leave-S+ data, a significant $\mathrm{S}+$ by $\mathrm{S}$ Change interaction $[F(1,28)=80.20, p<.01]$ and a significant interaction of these two factors with days of training $[F(9,252)=12.50, p<.01]$ were found. Partitioning the $\mathrm{S}+$ by $\mathrm{S}-$ interaction revealed that the $S+c \cdot S-c$ group $(\bar{X}=14.40)$ left the $S+$ alley more frequently than the $\mathrm{S}+{ }_{\mathrm{nc}} \cdot \mathrm{S}-_{\mathrm{nc}}$ group $(\overline{\mathrm{X}}=$ 10.68) $[F(1,28)=4.93, p<.05]$. The $S+_{n c} \cdot S-c$ and $\mathrm{S}+{ }_{\mathrm{c}} \cdot \mathrm{S}-_{\mathrm{nc}}$ groups did not differ in leave-S+ responses $(\overline{\mathrm{X}} \mathrm{s}=1.24$ and 2.44 , respectively, $\mathrm{F}<1)$ but collectively left the $\mathrm{S}+$ alley following initial $\mathrm{S}+$ entry significantly less often than the collective groups not receiving differential information $\left[S+{ }_{n c} \cdot S-S c\right.$ and $\mathrm{S}+{ }_{c} \cdot \mathrm{S}-\mathrm{c}, \overline{\mathrm{X}}=12.54 ; \mathrm{S}+{ }_{n c} \cdot \mathrm{S}-{ }_{\mathrm{c}}$ and $\mathrm{S}+_{\mathrm{c}} \cdot \mathrm{S}-{ }_{\mathrm{nc}}$, $\bar{X}=1.84 ; F(1,28)=76.21, p<.01]$. No other reliable effects were found.

The correct-to-S+ data yielded comparable results, except that mean differences were precisely opposite in direction to those of the leave-S+ curves. For the correct-to-S+ data, a significant $\mathrm{S}+$ by 
S- Change interaction $[F(1,28)=33.07, p<.01]$ and an interaction of these factors with days of training $[F(9,252)=12.50, p<.01]$ were found. Partitioning of the interaction revealed that the $\mathrm{S}+{ }_{n c} \cdot S-n c$ and $\mathrm{S}+_{c} \cdot \mathrm{S}-_{c}$ groups did not differ $(\overline{\mathrm{X}} \mathrm{s}=2.99$ and 4.50 , respectively, $\mathrm{F}<1$ ), nor did the $S+_{n c} \cdot S-c$ and $\mathrm{S}+_{\mathrm{c}} \cdot \mathrm{S}-{ }_{n c}$ groups differ $[\overline{\mathrm{X}} \mathrm{s}=12.15$ and 8.83 , respectively; $F(1,28)=4.02, p=.0547$ ], but the combined groups without the differential cue corrected to $\mathrm{S}+$ significantly less often $(\overline{\mathrm{X}}=3.75)$ than the combined groups with the differential cue $(\bar{X}=10.49)$ $[F(1,28)=32.61, p<.01]$. No other significant effects were found.

It is clear from these data that the differentially cued groups did not learn an indiscriminate secondresponse pattern. However, the $\mathrm{S}+_{c} \cdot \mathrm{S}-{ }_{c}$ group was expected to acquire the double-response pattern because double responding would provide, by the changed cues in both alternative alleys, definitive information on each trial that both alleys had been visited. Figure 3 suggests that the $\mathrm{S}+_{c} \cdot \mathrm{S}-_{c}$ group does double respond more often than the control levels shown by the $\mathrm{S}+_{n c} \cdot \mathrm{S}-{ }_{n c}$ group, but the above analyses only confirmed part of this expectation. The $\mathrm{S}+_{c} \cdot \mathrm{S}-{ }_{c}$ group left the $\mathrm{S}+$ alley more often than the $S+{ }_{n c} \cdot S-{ }_{n c}$ control, but the groups did not differ in corrections to the S+ alley.

ITI responses. The last analysis considered the mean number of alley changes during the ITI. A decrease from 51.8 on the first day to 36.7 on the last day of training $[F(9,252)=6.74, p<.01]$ was the only significant effect found.

Taken as a whole, the initial- and second-response analyses leave no doubt that goldfish learned a discriminated avoidance response based solely on differential response-contingent cues. There are at least two possible explanations for these findings. One can assume, as in Experiment 1, that goldfish learned to leave shock-paired cues. This would explain why all animals learned an initial response of leaving the start alley and approaching an alternative alley. But this simple conditioned-aversion explanation does not account for the acquisition of a discriminated second response. Specifically, the discriminated second response involved leaving the $\mathrm{S}$ - alley and correcting to the $\mathrm{S}+$ alley given the initial response was to the $S-$ alley. When the $S-$ alley cue changed contingent upon initial approach $\left(\mathrm{S}-{ }_{\mathrm{c}}\right)$, and the changed cue was paired with shock, it is easy to see why goldfish learned to leave the $\mathrm{S}-{ }_{c}$ cue condition. The $\mathrm{S}-{ }_{\mathrm{c}}$ condition, being specifically paired with the US, would become an aversive cue. But when the $S$ - cue did not change when initially approached $(\mathrm{S}-\mathrm{nc})$, the animal had approached a cue which presumably was less aversive than the start alley cue, and, following the approach response, had to learn to leave it and swim to the remaining alley. Thus, the $S_{-}{ }_{n c}$ cue must elicit both approach (initial response) and aversion (second response) for the animal to successfully avoid. Thus, one would expect that learning to leave the $\mathrm{S}$ - alley and correct to the remaining $\mathrm{S}+$ alley would be easier when the $S$ - cue changed contingent upon initial approach $(\mathrm{S}-\mathrm{c})$ than when it did not $\left(\mathrm{S}-{ }_{\mathrm{nc}}\right)$. There is some support for this expectation in that the $S+_{n c} \cdot S-c$ group learned to correct to $\mathrm{S}+$ faster than the $\mathrm{S}+_{\mathrm{c}} \cdot \mathrm{S}-{ }_{\mathrm{nc}}$ group (see Figure 3), but, although in the proper direction, this difference was not statistically reliable.

Another explanation would be to assume that the goldfish was using the change/no-change cue as response-feedback information which merely served to tell the animal the state of its environment following its initial response. Thus, change/no-change served as the differential cue indicating whether or not further environmental modification, and response, was required (Bolles, 1970). Feedback explanations to account for conditioned avoidance in the shuttlebox have been offered before (Woodard \& Bitterman, 1973) but have assumed intrinsic feedback from the shuttling response itself rather than feedback from a differential external cue. The intrinsic feedback hypothesis cannot account for the present data because such feedback would occur on every trial with an initial response and would not explain how or why the goldfish swims directly to one cued alley over another. This would be especially true in Experiment 1, in which goldfish learned to swim directly to the alley showing the US omission cue.

\section{GENERAL DISCUSSION}

Woodard and Bitterman (1973, p. 128) stated that, "It seems then that all of our data on avoidance conditioning in goldfish can be accounted for without reference to a process of instrumental learning," and "Whether there is anything like instrumental avoidance learning in goldfish remains, therefore, to be demonstrated." Although other investigators have found higher responding during the CS-US interval when the US could be avoided, substantial response levels occurred when the US was not avoidable (Scobie \& Fallon, 1974; Zerbolio \& Wickstra, 1978a, 1978b). In passive avoidance paradigms, although goldfish learned to inhibit shuttling during CS presentations compared with yoked controls (Woodard \& Bitterman, 1973), additional work showed comparable response inhibition with no CS at all (Zerbolio \& Wickstra, 1978 c). With successive presentation of two stimuli, both Woodard and Bitterman (1971) and Zerbolio and Wickstra (1979a) showed that goldfish learned to respond to the US paired signal but not to the unpaired signal. However, a similar discrimination was found using the explicitly unpaired pseudoconditioning procedure when responses in 10 -sec portions of 
the ITI just prior to shock were compared with responses in CS priods (Zerbolio \& Wickstra, 1979a). In addition, response-contingent CS termination has not been found to play an important role in avoidance acquisition in goldfish (Scobie \& Fallon, 1974; Woodard \& Bitterman, 1973; Zerbolio \& Wickstra, 1978a, 1978b, 1978c, 1979a).

These results occur, at least in part, because goldfish continue to respond in many paradigms involving aversive stimuli. This response characteristic was clearly anticipated by Steiner (1971), who found that, instead of habituating over days, no-shock controls showed acquisition of shuttling behavior. Interpretation of results from any paradigm using shock motivation must take this behavioral characteristic into account. The simultaneous-presentation procedure clears up much of the confusion found in earlier studies, because the learning measure is based on active choice behavior rather than on activity increase or decrease per se.

With the use of the simultaneous-presentation procedure, goldfish clearly learned to swim to a cued alley of the $\mathrm{Y}$-maze associated with US omission and/or to avoid cued alleys associated with US presentation. Selection of the cued shock-free alley, either by positive approach or conditioned aversion to shock-paired alleys, occurred when the $S+$ and $\mathrm{S}-$ cues were presented at trial onset as in Experiment 1 , or when access to the $S+$ and $S-$ cues required an initial response, as in Experiment 2. In both experiments, goldfish learned to use the available cue information to avoid shock. It seems reasonable to conclude that these results represent a demonstration of discriminated avoidance acquisition based on an underlying instrumental process. Also important is the finding that goldfish will continue to respond even when they cannot determine which alley will be paired with shock, as in the $\mathrm{S}+{ }_{n c} \cdot \mathrm{S}-{ }_{n c}$ procedure of Experiment 2. As long as the animal continues to respond, differential response-contingent reinforcement is possible. Because of this tendency to respond, goldfish may be the appropriate laboratory preparation to use in complex shock-motivated experiments along the lines typically limited to posi- tive reinforcement paradigms and thereby allow further comparisons of performance based on positive and negative reinforcement.

\section{REFERENCES}

Bolles, R. C. Species-specific defense reactions and avoidance learning. Psychological Review, 1970, 77, 32-48.

RYBACK, R. S. State-dependent or dissociated learning with alcohol in the goldfish. Quarterly Journal of Studies on Alcohol, 1969, 30, 598-608. (a)

RYBACK, R. S. Effect of ethanol, bourbon, and various ethanol levels on Y-maze learning in the goldfish. Psychopharmacologia, 1969, 14, 305-314. (b)

Sahagian, D. E., \& Ingle, D. J. The effects of amphetamine on maze learning by goldfish. Psychopharmacology, 1977, 53, 319-320.

Scobie, S. R., \& Fallon, D. Operant and Pavlovian control of a defensive shuttle response in goldfish (Carassius auratus). Journal of Comparative and Physiological Psychology, 1974, 86, 858-866.

Steiner, G. Stimulus control of avoidance learning in fish. Journal of Comparative and Physiological Psychology, 1971, 74, 52-58.

Woodard, W. T., \& Bitterman, M. E. Classical conditioning of goldfish in the shuttlebox. Behavior Research Methods \& Instrumentation, 1971, 3, 193-194.

Woodard, W. T., \& Bitterman, M. E. Pavlovian analysis of avoidance conditioning in the goldfish (Carassius auratus). Journal of Comparative and Physiological Psychology, 1973, 82, 123-129.

Zerbolio, D. J., JR., \& Wickstra, L. L. Goldfish avoidance acquisition: Is the process classical, instrumental, or phototaxis? Bulletin of the Psychonomic Society, 1978, 11, 321-323. (a)

ZERbolio, D. J., JR., \& Wickstra, L. L. Does elimination of a negative phototaxis eliminate CAR acquisition in goldfish? Bulletin of the Psychonomic Society, 1978, 11, 324-326. (b)

Zerbolio, D. J., JR., \& Wickstra, L. L. Passive avoidance in goldfish: Lack of evidence for stimulus specificity. Bulletin of the Psychonomic Society, 1978, 12, 15-17. (c)

Zerbolio, D. J., Ja, \& Wickstra, L. L. Discriminated response patterning in goldfish with successive presentation and explicitly unpaired pseudoconditioning procedures. Bulletin of the Psychonomic Society, 1979, 13, 307-310. (a)

ZERBoLio, D. J., JR., \& Wickstra, L. L. Instrumentally based conditioned avoidance response acquisition in goldfish in a simultaneous presentation task. Bulletin of the Psychonomic Society, 1979, 13, 311-313. (b)

(Received for publication March 13, 1979; revision accepted October $29,1979$. 